\title{
On the Process of Adaptation of MOOCs to the EdX Platform: A Case Study
}

\author{
A.J. Guirao, A. Herrero, S. Moll, J.-A. Moraño \\ Dpto. Matemática Aplicada, Universitat Politécnica de Valencia
}

\begin{abstract}
In the last years, supported by the Technical University of Valencia, several MOOC's have been developed with the aim to ease the learning process and expanding the knowledge needed by the students. In this context we introduced at the $U P V[X]$ platform four MOOC's entitled 'Basic Mathematics: Numbers and Terminology, Derivatives, Integrals and Algebra' covering basic mathematics topics students need for the first year in the different degrees of engineering. A few months ago UPV became a member of the EdX network and as a consequence the scope of Basic Mathematics courses increased exponentially. This implied a necessary adaptation of the contents, a much more progressive approach and an improvement in the assessment method. In this paper we report the changes made in the process of adaptation to the EdX platform, presenting the results obtained and suggesting improvements in the assessment of the MOOCs. Also an analysis of the opinions of the students is presented.
\end{abstract}

\section{Introduction}

Massive Open Online Courses (MOOCs) are classes delivered in an online environment with significant differences from previous approaches to online education. MOOCs are free and open to all, attracting larger audiences than traditional online education. The term MOOC was first used to describe an online open course entitled 'Connectivism and Connective Knowledge (CCK08)' by George Siemens and Stephen Downes (Manitoba University) that had over 2200 participants, although this is a controversial situation because there are many others courses claiming to be first MOOC.

Following [1] the fundamental characteristics of a MOOC are:

- Open: Participation in a MOOC is free and open to anyone who has access to the Internet. The work that is generated through the course (both by the facilitators and learners) is shared and available publicly. Finally, there is openness in terms of the learner's role.

- Participatory: The learning in a MOOC is enhanced by participation both in the creation and sharing of personal contributions and in the interactions with the contributions of others but the participation is voluntary.

- Distributed: MOOC is normally based on the connectivist approach; therefore, any knowledge should be distributed across a network of participants. Most of the course activity takes place in social learning environments, where participants interact with the material (and each other's' interpretations of it). The course learning materials available act as starting points for discussion and further thinking.

However, in [2] two types of MOOCs are presented and discussed. The first one is based on the connectivism theory of learning aforementioned, which stimulates networks of learners evolving informally. These are known as cMOOCs. The type known as xMOOCs are more closely resemble traditional educational models, more likely to have one lecturer via YouTube style videos, with tasks and discussions taking place online. This type of MOOCs allows the university to incorporate them into the existing curricula. Deadlines for completing tasks, and an online form of continuous assessment allow the course administrators to assign marks and credits. Online participants who are not interested in obtaining credits can participate.

xMOOCs remained relatively unknown until 2011 when a number of the leading Universities in the United States began to offer MOOCs via commercial platforms such as Coursera, Udacity or EdX.

Since 2012, a growing number of universities have offered MOOCs worldwide and the public and academic discourse around MOOCs has been strengthened. MOOCs have been recognized as a major advancement of higher education [3].

Students enroll in MOOCs for a variety of reasons. Curiosity and studies complement, for example, are common motivating factors [4]. A limited amount of research has studied the factors that influence MOOC accomplishment and even fewer, the continued completion of MOOCs.

Most of the MOOCs in the aforementioned platforms follow a common structure in which we can find:

- Video lectures with various presentation styles, from talking heads to lecturing instructors. The usual running time for the lecture videos is 5-10 minutes each with in video quizzes embedded. 
- Assessment through the use of auto-graded multiple choice questions or programming assignments, and peer review assessment where students themselves evaluate and grade assignments based on a defined rubric set.

- Forums where students post questions and other students replies, and are the main method of student interaction between course takers and instructors. Forums usually consist of general discussion, subject-specific discussion, course feedback, and technical feedback threads.

- Readings are normally available online or provided by course instructors.

- Live video sessions in addition to the weekly lectures with the course instructor.

- Activities are offered, with the aim of allowing students to further test their understanding of the course concepts.

- Additional video resources to help comprehension of scenes.

- Social media where students are encouraged to continue their discussions, such as Facebook and Google+.

As we can find in [5], the impact of MOOCs goes beyond providing free and open education and is now leading to new blended learning scenarios at schools and universities. In these contexts, MOOCs are exploited to enhance teaching and learning in the form of successful flipped classrooms (i.e. students watch videos with the theoretical concepts from home and practice these concepts with automatic correction exercises, and later attend to the classroom to solve problems with teachers). Such use of the affordances that emerge from MOOCs to improve the quality of teaching and learning in traditional educational settings leads to what has been called SPOCs (Small Private Online Courses) in the media [6].

In this context, Technical University of Valencia has been developing MOOCs, with the aim to ease and supplement the learning process of the students. These courses have a strong potential and they can be used in many areas, especially at university level and secondary education. These courses can introduce new topics and subjects or to reinforce previous knowledge [7].

In collaboration with the Department of Applied Mathematics (DMA) we have presented a collection of four MOOCs entitled Basic Mathematics: Numbers and Terminology, Derivatives, Integrals and Algebra covering the basics mathematics that students need the first year of the different degrees at engineering schools. This courses were first delivered through the UPV platform, UPV [X], meant for a national scope. The objectives sought were to match freshmen level in mathematics, to improve the motivation, to avoid dropouts and to help students achieving the specific skills they need faster.
Nevertheless, UPV has become a collaborating member of the EdX platform in the last months, and as a result the scope of Basic Mathematics courses has increased exponentially, implying an adaptation of the contents, a much more progressive apprenticeship and an improvement in the assessment method. In this paper we present the changes applied in the adaptation process to the EdX platform and the results and opinions of the participants.

The objectives of the adaptation process were:

- To adapt MOOCs to the new EdX platform.

- To improve the methodology so it fits better to a broader and more diverse audience.

- To reduce the length of the videos when possible.

- To apply an assessment method that fits the different backgrounds of the participants.

- To evaluate the academic performance and the opinions of the participants.

\section{Procedure}

Based on Basic Mathematic courses made to the UPV $[X]$ platform, we have introduced significant changes with respect to the content and the assessment in order to adapt them to a wider audience [8]. For the modifications we have used the editing tool of the EdX platform, called EdX Studio.

Relevant changes that have been applied are:

- Language: we attempted to use a language as neutral as possible, reviewing the texts. MOOCs are oriented for Spanish-speaking participants, but because of the dialectical differences between countries many words change their meaning. We have tried to avoid all those words that would change its meaning. In addition, we have used a more formal tone throughout the course.

- Content: We have shortened the length of the videos to get an average of 8 minutes per video. The length of the videos is very important for motivating students since it has been studied that a length greater than 10 minutes discourages course participants

When necessary we have fragmented the units to distribute the important concepts in several explanations.

On the other hand, we have tried to improve the educational part of the presentations, increasing the number of examples, and reviewing the theoretical explanations [9]. We have also restructured the units of the MOOCs to make them more attractive for the students. We had special care organizing the sequence of units to make the learning process as progressive as possible.

Finally, we have tried to encourage active participation in the forum in order to identify gaps and weaknesses in the knowledge of the participants. In this regard, when necessary we have provided 
additional material (videos or texts) and useful references.

- Assessment: Assessments have been revised in detail. We have tried to sort the questions by order of increasing difficulty to keep the student motivated. The difficulty we want to achieve is the one posing a challenge to the student but achievable with some effort.

In order to reinforce the learning process, each assessment contained different basic notions already evaluated in past tests, in order to keep updated.

- Opinions: As in previous editions, a survey has been conducted. We have tried to determine the success of the applied changes. Apart from the survey EdX normally conducts after the realization of each MOOC, we have been able to extend this poll to a medium-size control groups in Biomedical, Industrial, Aerospace and Electrical Engineering. In all cases the poll was available for all participants via a link in the $\mathrm{EdX}$ platform or through the UPV $[\mathrm{X}]$ platform.

\section{Results}

In this section we will report the data collected through the EdX and UPV $[X]$ platform. Results are very similar for the four courses. For these reason we will omit the unnecessary data, keeping the eye in the most interesting results.

\subsection{Basic Mathematics: Differentiability}

The number of the participants completing the course was 3002. These participants formed a heterogeneous group with many different ages and nationalities. As seen in Figure 1 age distribution is strongly disperse, although there exists a bigger density in the interval between 18 and 32. Average age has been 27 years old.

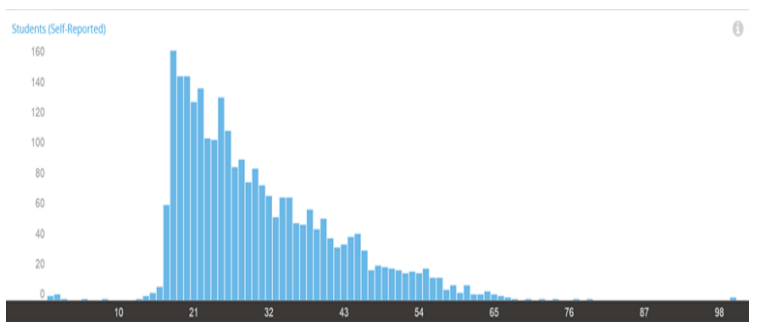

Figure 1. Age distribution of the participants

From the data obtained from the participants we can observe that $42.8 \%$ of them are younger than 25 , $34.5 \%$ are between 26 and 40, and $18.6 \%$ are older than 41 years old.

Apart from the age, background studies are also very different. It is worth noting that most of the participants had secondary education (31.1\%), followed by bachelor (29.1\%) and master (22.3\%) students as seen in Figure 2.

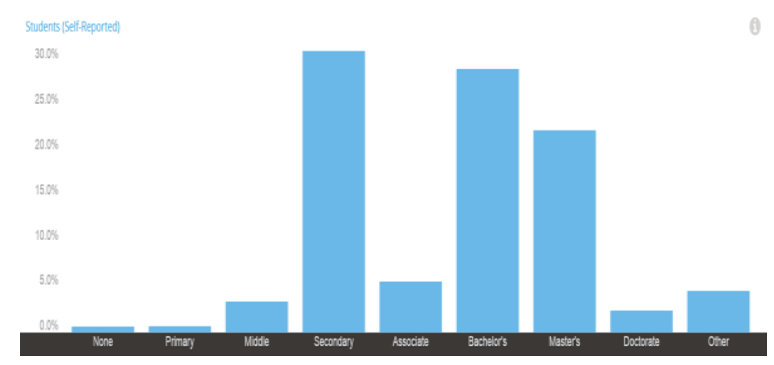

Figure 2. Studies distribution of the participants

Finally, the geographical distribution of the participants is very broad, although the highest values are concentrated in Spanish-speaker countries. Participants from 82 countries have completed this MOOC, being Spain the country with more participants $(21 \%)$, followed by Mexico (18\%) and Colombia (12\%) (see Figure 3).

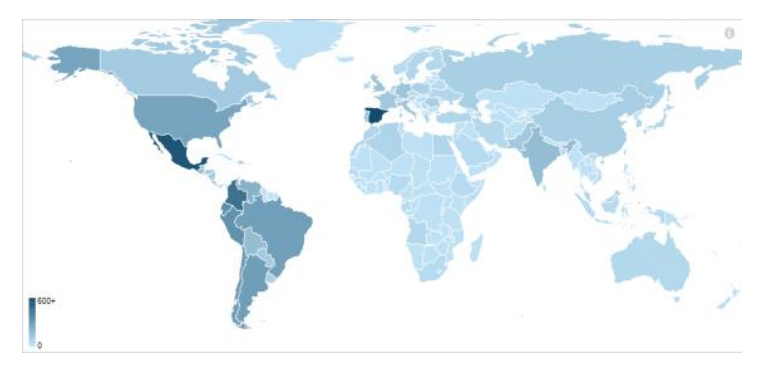

Figure 3. Geographical distribution of the participants

More details can be seen in Figure 4.

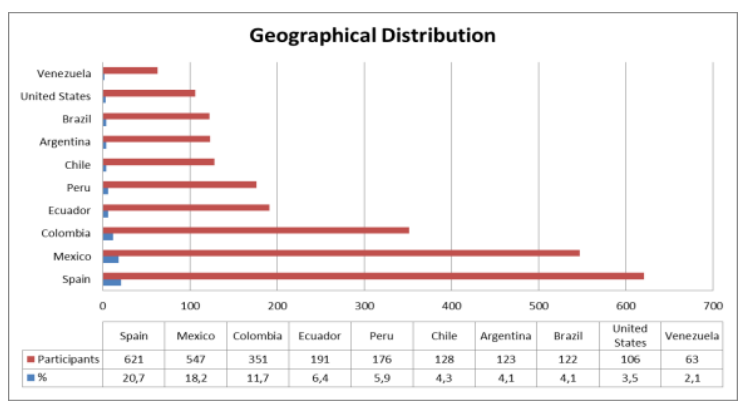

Figure 4. Geographical Distribution

With regard of the genre, $74.4 \%$ of the participants were male and $25.3 \%$ female.

The course Basic Mathematics: Differentiability is divided in 5 units: Definition and types of functions, definition of differentiability, calculus of derivatives, optimization and conditioned optimization. Figure 5 shows the success values at each unit. As it can be seen, $88 \%$ of the participants have passed successfully the final test. We have tried 
to increase the difficulty of the assessments smoothly and this fact has affected the number of students who passed the tests. Final evaluation reached $88.8 \%$ of success.

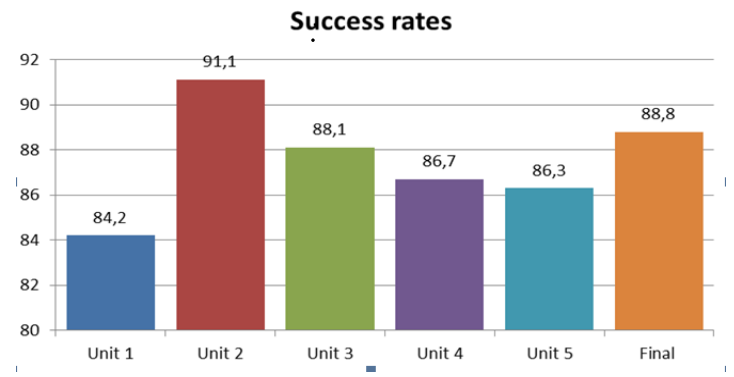

Figure 5. Success rate in Basic Mathematics: Differentiability

\subsection{Basic Mathematics: Numbers and Terminology}

The number of participants was 2286. As in the course of derivatives, it was made up of a diverse group of different origins and ages. As seen in Figure 5 the distribution of ages shows higher density in the range between 18 and 43. The average age was 29 years.

From the data we know that $36.7 \%$ are below 25 years old, $36.1 \%$ are aged between 26 and 40 years and $23.5 \%$ are over 41 years old.

As in the case of Differentiability, the educational level of the participants it is very broad although most participants had a level corresponding to secondary studies $(31 \%)$, followed by university studies $(26.8 \%)$ and masters (23.2\%) (see Figure 6).

In terms of geographical distribution of the participants we have obtained very similar results as in the Differentiability MOOC.

This course is divided in three units: Terminology and Basic Concepts, Numerical sets and Complex numbers. In Figure 5 success rates in the evaluation of each unit are shown. In this case, the percentages are higher, although this may be due to the lower level of difficulty of the concepts evaluated. The unit with the lowest pass rate has been Complex Numbers unit.

\section{Success rates}

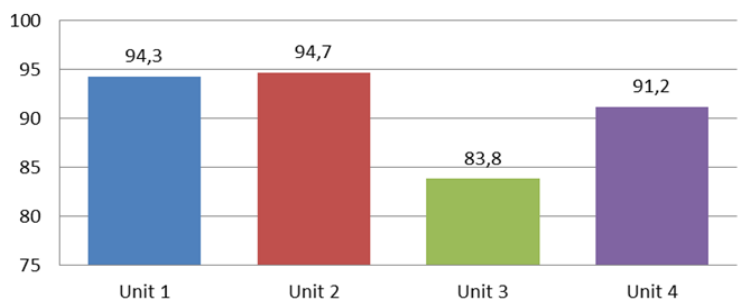

Figure 6. Success rate in Basic Mathematics: Numbers and Terminology.

\subsection{Basic Mathematics: Algebra}

The number of participants in this course is 3385 . As in previous courses participants form a heterogeneous group with different backgrounds and ages. As seen in Figure 8 the age distribution shows greater density in the range between 18 and 32. The average age was 27 years. From the data we know that $44.6 \%$ are below 25 years old, $33.4 \%$ are aged between 26 and 40 years and $18 \%$ are over 41 years old.

The level of education of participants is varied although as in most previous cases correspond to secondary $(33.8 \%)$, university studies $(28.4 \%)$ and masters $(20.1 \%)$.

This MOOC is divided in 3 units. In Figure 7 the success rates in the evaluation of each unit are shown.

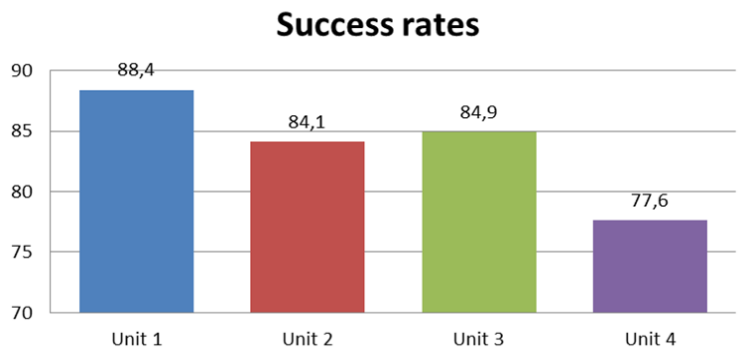

Figure 7. Success rate in Basic Mathematics: Algebra

\subsection{Basic Mathematics: Integrals}

For this course we have obtained very similar results to those obtained in other courses, except for the success rates that are a little lower.

\subsection{Polls}

We have surveyed 50 students in order to obtain their opinion on different aspects of the courses. Some of the results are presented. As it can be seen in Table 1, most of the students think that the MOOCs have been useful.

Table 1. Opinion on the usefulness of the MOOCs

\begin{tabular}{|l|c|}
\hline $\begin{array}{c}\text { Were the MooCs helpful } \\
\text { for you? }\end{array}$ & Answers \\
\hline Nothing & $0 \%$ \\
\hline A Little & $10.9 \%$ \\
\hline Indifferent & $9 \%$ \\
\hline Much & $60.5 \%$ \\
\hline A Lot & $19.6 \%$ \\
\hline No answer & $0 \%$ \\
\hline
\end{tabular}


One of the changes applied has been the assessment of the sessions. The data provided is shown in Table 2.

Table 2. Opinion on the assessments

\begin{tabular}{|l|c|}
\hline $\begin{array}{l}\text { Are the assessments fitted } \\
\text { with the difficulty of the } \\
\text { MOOC? }\end{array}$ & Answers \\
\hline Nothing & $0 \%$ \\
\hline A Little & $15.8 \%$ \\
\hline Indifferent & $27 \%$ \\
\hline Much & $57.2 \%$ \\
\hline
\end{tabular}

The answers related with the language and the content are shown in Table 3.

Table 3. Opinion on the language and content

\begin{tabular}{|l|c|}
\hline $\begin{array}{c}\text { Are the explanations } \\
\text { and the language easy } \\
\text { to understand? }\end{array}$ & Answers \\
\hline Nothing & $0 \%$ \\
\hline A Little & $8 \%$ \\
\hline Indifferent & $20 \%$ \\
\hline Much & $52,4 \%$ \\
\hline A Lot & $19,6 \%$ \\
\hline No answer & $0 \%$ \\
\hline
\end{tabular}

The answers related with the material provided during the course are shown in Table 4.

Table 4. Opinion on the material of the MOOCs

\begin{tabular}{|l|c|}
\hline $\begin{array}{c}\text { Did you find } \\
\text { useful the extra } \\
\text { material } \\
\text { nrovided? }\end{array}$ & Answers \\
\hline A Little & $2 \%$ \\
\hline Indifferent & $17 \%$ \\
\hline Much & $12.8 \%$ \\
\hline A Lot & $68.2 \%$ \\
\hline No answer & $0 \%$ \\
\hline
\end{tabular}

\section{Conclusions}

The incorporation of the University UPV as a partner in the EdX platform has meant a significant increase of participants in the courses of Basic Mathematics: Numbers and terminology, Algebra, Differentiability and Integrals. Besides the increase in number, the fact that participants come from different countries has been a challenge to standardize courses so that they are affordable for most users.

The changes related to the assessment, content, additional material and language have provided very good results. In addition, the opinion expressed by the students surveyed indicated a high appreciation of the modified aspects.

We have yet to detect units with a success rate lower than expected, so we should check both the difficulty and the order of presentation of the contents to optimize the learning process of the participants.

Success rates have been higher than in previous calls even though the number of students of this platform is five times the number in the UPV $[\mathrm{X}]$ platform.

\section{Acknowledgements}

The authors would like to thank the Department of Applied Mathematics for the Teaching Innovation Projects, PID-DMA-2014, which funds this research.

\section{References}

[1] M. Huri Baturay, "An overview of the world of MOOCs", Procedia - Social and Behavioral Sciences, 174, 2015, pp. 427-433.

[2] D. El-Hmoudova, "MOOCs Motivation and Communication in the Cyber Learning Environment", Procedia - Social and Behavioral Sciences, 131, 2014, pp. 29-34.

[3] A. Margaryan, M. Bianco, A. Littlejohn, "Instructional quality of Massive Open Online Courses (MOOCs)", Computers \& Education, 80, 2015, pp. 77-83.

[4] K. M. Alraimi, H. Zo, A.P. Ciganek, "Understanding the MOOCs continuance: The role of openness and reputation", Computers \& Education, 80, 2015, pp. 28-38.

[5] P.J. Muñoz-Merino et al, "Precise Effectiveness Strategy for analyzing the effectiveness of students with educational resources and activities in MOOCs", Computers in Human Behavior, 47, 2015, pp. 108-118.

[6] Coughlan, S. (2013). Harvard plans to boldly go with 'Spocs', BBC News Business.

<http://www.bbc.co.uk/news/business-24166247>.

[7] J.M. Aiken et al. "The initial state of students taking an introductory Physics MOOC", PERC Proceedings, Cornwell University, 2013, pp. 295-309.

[8] S. Kellogg. "Online learning: how to make a MOOC", Nature, vol. 499, pp. 369-371 (2013).

[9] C. King, A. Robinson, J. Vickers. "Online education: Targeted MOOC captivates students", Nature, vol. 505 (2014). 